\title{
Cuidado Perioperatório ortopédico: olhar do paciente, equipe de enfermagem e residentes médicos
}

\section{Orthopedic Perioperative Care: viewpoint of the patient, nursing staff and medical residents}

\author{
Josilaine Porfírio da Silva ${ }^{1}$; Elizabete Rosane Palharini Yoneda' ${ }^{2}$ Isabella Rita do \\ Amaral Saragiotto $^{3}$; Jessica Mayumi Hayashi ${ }^{4}$; Mara Lucia Garanhani ${ }^{5}$
}

\begin{abstract}
Resumo
O objetivo deste estudo foi identificar as ações de cuidado perioperatório realizadas com o paciente cirúrgico ortopédico na visão da equipe cirúrgica e do próprio paciente. Pesquisa qualitativa descritiva e exploratória, realizada com 20 profissionais da saúde e oito pacientes submetidos à cirurgia ortopédica, no período de outubro de 2009 a julho de 2011. A coleta de dados deu-se por meio de entrevista semiestruturada abordando questões relacionadas ao cuidado e ao autocuidado com pacientes submetidos à cirurgia ortopédica. Os resultados foram organizados em três categorias: (a) Significado de cuidado: abrangeu assistência integral, prevenção de prejuízos e cuidados subjetivos; (b) Necessidades dos pacientes ortopédicos percebidas pela equipe de saúde: evidenciou as necessidades humanas básicas e específicas; (c) Ações de cuidado: revelou indicação cirúrgica, avaliação do tempo de espera, utilização de materiais especiais e risco cirúrgico. A partir das necessidades percebidas é que o cuidado acontece, seu significado é dinâmico e atemporal. Este estudo evidenciou que o significado de cuidado permaneceu relacionado ao processo saúde-doença.
\end{abstract}

Palavras-chave: Cuidado ortopédico. Cuidados perioperatórios. Enfermagem ortopédica.

\begin{abstract}
The aim of this study was to identify the actions of perioperative care taken with the orthopedic surgical patient in view of the surgical team and the patient. Qualitative descriptive and exploratory research, conducted with 20 professionals, in the period from October 2009 to July 2011. Data collection took place by means of a semi-structured interview addressing issues related to care and self-care to patients undergoing orthopedic surgery. Results were arranged into three categories: (a) Meanings of perioperative care: covered integral assistance, prevention of damage and care subjective; (b) patients' needs perceived by health team: evidenced basic and specific human needs; (c) Actions of care: surgical indication, evaluation revealed the wait, use of special materials and surgical risk. From the perceived needs is that care happens, its meaning is dynamic and timeless. This study showed that the meaning of care remained related to the health-disease process.
\end{abstract}

Keywords: Orthopedic care. Perioperative care. Orthopedic nursing.

\footnotetext{
${ }^{1}$ Mestre em Enfermagem pela Universidade Estadual de Londrina. Enfermeira no Hospital Zona Sul de Londrina. Londrina, Paraná, Brasil.

${ }^{2}$ Graduada do curso de Enfermagem da Universidade Estadual de Londrina (UEL). Londrina, Paraná, Brasil.

${ }^{3}$ Residente do Programa de Residência em Enfermagem Perioperatória da Universidade Estadual de Londrina. Londrina, Paraná, Brasi

${ }^{4}$ Graduada do curso de Enfermagem da Universidade Estadual de Londrina (UEL). Londrina, Paraná, Brasil.

${ }^{5}$ Doutora em Enfermagem. Professora associada da Graduação e Pós-graduação do curso de Enfermagem da Universidade Estadual de Londrina (UEL). Londrina, Paraná, Brasil.
} 


\section{Introdução}

O cuidado é característica constituinte da raça humana, descrito e experienciado desde os primórdios, demonstrando ser uma atitude essencial à existência humana e ao desenvolvimento do ser (WALDOW; BORGES, 2011). O cuidado em saúde deve buscar o equilíbrio entre ação e atenção, no qual a terapêutica contemple às atividades técnicas e o combate à doença, bem como, a valorização do sofrimento e sentimentos vivenciados pelo doente. Este é sem dúvida, um desafio ético, no qual a ação não se sobrepõe à atenção, e a assistência resultante deste equilíbrio, permite um cuidado de qualidade, prestado ao ser humano, de forma humanizada (MELLO; LIMA, 2010; QUEIROZ; RIBEIRO; PENNAFORT, 2010).

A enfermagem, por sua vez, é uma profissão que tem como essência de sua atividade o cuidado à pessoa, família e comunidade, no seu processo saúdedoença, estando suas atividades e responsabilidades voltadas para esta ação (MELLO; LIMA, 2010). No seu ambiente de trabalho lida com as mais diversas necessidades de cuidado, dentre elas, o cuidado aos pacientes que necessitam de uma intervenção cirúrgica.

O período perioperatório compreende um momento complexo, que envolve desde o diagnóstico, a decisão pela cirurgia, a recuperação e a reabilitação, pode ser acompanhado por diversos sentimentos como ansiedade, insegurança e medo do desconhecido (HAYASHI; GARANHANI, 2012; STUMM et al., 2009). O período pré-operatório inclui o preparo do paciente, sendo que este deve receber a visita da equipe, que dará orientações sobre o procedimento anestésico-cirúrgico que será empregado. O período trans-operatório está relacionado com a realização do procedimento cirúrgico em si. Operíodo pós-operatório é determinado pela assistência ao paciente desde a sala de recuperação anestésica, até seu retorno à unidade de internação ou unidade de tratamento intensivo (SOCIEDADE BRASILEIRA DE ENFERMEIROS DE CENTRO CIRÚRGICO, 2013).

Neste contexto, ganham destaque as cirurgias ortopédicas, frente ao aumento constante dos traumas, relacionado com a crescente velocidade de locomoção do ser humano. No Brasil, as causas externas representam a terceira causa de mortalidade $(14,4 \%)$, o aumento dos acidentes repercute na organização do sistema de saúde e nos gastos dispensados ao atendimento deste grupo. Entre os anos de 1998 e 2005, houve um aumento progressivo $(1,7 \%)$ nas internações por esta causa, assim como, nos gastos $(2,1 \%)$ com as internações. Os acidentes de trânsito terrestre, aéreo ou mesmo doméstico podem acarretar fraturas ósseas complexas, com perdas sanguíneas importantes (BRASIL, 2010; MELIONE; MELLO-JORGE, 2008).

A ortopedia é a especialidade médica que cuida das doenças e deformidades dos ossos, músculos, ligamentos, articulações, enfim, doenças relacionadas ao aparelho locomotor. A traumatologia é a especialidade médica que lida com o trauma do aparelho músculo-esquelético que podem acarretar em fraturas fechadas ou expostas (ROTHROCK, 2007). No Brasil as especialidades são unificadas, recebendo o nome de Ortopedia e Traumatologia.

Dentre os cuidados na cirurgia ortopédica, destacam-se o posicionamento cirúrgico, preparo cutâneo, equipamentos adequados e instrumentação, conforme o tipo de cirurgia a ser realizada. No período pós-operatório das cirurgias ortopédicas são agregados cuidados quanto à mudança de decúbito, imobilização, curativos, dor, complicações, como infecção, tromboembolismo, assim como reabilitação, uso de aparatos para deambulação, como muletas, manutenção da autonomia (ROTHROCK, 2007).

Frente à relevância das afecções ortopédicas no cenário nacional, principalmente por sua alta mortalidade, gastos elevados com as internações, necessidade de intervenções de alta complexidade e demanda de cuidados específicos, consideramos ser necessário compreender quais as percepções dos profissionais e pacientes sobre esses atendimentos. Como o cuidado não é algo que acontece apenas individualmente, é importante saber como o mesmo 
é entendido, realizado e vivido sob diferentes olhares. Assim, indagamos como o cuidado está sendo realizado por profissionais médicos e de enfermagem em um hospital escola na clínica de ortopedia? Quais as necessidades de cuidado apresentadas pelo paciente ortopédico e equipe cirúrgica?

Desta forma, o objetivo desta pesquisa foi identificar as ações de cuidado perioperatório realizadas com o paciente cirúrgico ortopédico na visão da equipe cirúrgica e do próprio paciente.

\section{Método}

Trata-se de uma pesquisa qualitativa, descritiva e exploratória.

O estudo foi realizado em um hospital universitário de grande porte, localizado no norte do Paraná. A instituição possui 333 leitos, todos disponíveis para o Sistema Único de Saúde, realiza em média 1.500 internações mensais, além de 12.000 atendimentos ambulatoriais, 2.700 atendimentos de pronto-socorro e 650 cirurgias. Os recursos humanos são representados por cerca de 310 docentes com atividade direta, 1.718 servidores do quadro técnico-administrativo, além de residentes das diversas especialidades e alunos de graduação.

A coleta de dados foi realizada no período de outubro de 2009 a julho de 2011 nas unidades de internação e centro cirúrgico deste hospital. Participaram do estudo oito pacientes submetidos à cirurgia ortopédica e 20 profissionais da saúde (cinco residentes médicos da clínica da ortopedia, seis enfermeiros e nove técnicos de enfermagem).

O recurso escolhido para a coleta dos dados foi a entrevista semi-estruturada, por considerar que esta possibilita captar os diferentes modos dos participantes vivenciarem o cuidado perioperatório. As perguntas orientadoras para a realização das entrevistas foram diferenciadas para os três grupos de participantes, visto que se buscou compreender o fenômeno de maneira específica para quem cuida e quem é cuidado.

Para os residentes médicos, da clínica de ortopedia, foram utilizadas as seguintes perguntas: Quais as necessidades de cuidado que você considera que o paciente cirúrgico apresenta? Como você cuida do paciente cirúrgico? Como você compartilha o cuidado do paciente cirúrgico? O que significa cuidado para você?

As perguntas orientadoras para os profisisonais de enfermagem foram: Descreva para mim a sua rotina de cuidado com o paciente cirúrgico da ortopedia. Quais os cuidados mais frequentes realizados com este paciente? Quais as necessidades de cuidado que você considera que o paciente cirúrgico da clínica de ortopedia apresenta? Você compartilha o cuidado do paciente cirúrgico da ortopedia com outros membros da equipe? Quais e em que situações (quando, como)? O que significa cuidado para você?

Quanto aos pacientes, foram utilizadas as seguintes perguntas orientadoras: Como você vivenciou o cuidado nos períodos pré, trans e pós-operatórios? Quem cuidou de você? O que é cuidado para você?

Somente foram utilizadas outras perguntas durante a entrevista quando houve necessidade de facilitar ou auxiliar a continuidade do depoimento. Estas perguntas foram: gostaria de falar mais alguma coisa sobre isto? Você quer me contar mais alguma coisa? Também foi utilizado o recurso de repetir a última frase dita pelo entrevistado, diante de pausas longas deste, possibilitando a continuidade ao seu pensar.

Para manter a fidedignidade das falas as entrevistas foram gravadas e transcritas na íntegra. Para construção dos resultados fez-se a aproximação dos dados encontrados em pesquisas anteriores, realizadas isoladamente com pacientes, equipe de enfermagem e residentes médicos da clínica de ortopedia (HAYASHI; GARANHANI, 
2012; SARAGIOTTO; GARANHANI, 2010). Para alcançar o objetivo deste estudo, estas três pesquisas foram retomadas e tiveram seus resultados relacionados. A análise dos resultados seguiu as etapas preconizadas por Martins e Bicudo (2005): análise ideográfica e nomotética.

A análise ideográfica refere-se à inteligibilidade dos significados presentes, que se articulam nas suas inter-relações e na sua unidade estrutural. A análise nomotética tem por objetivo alcançar a estrutura geral psicológica, proporcionando um movimento de convergências e divergências, que se mostraram nos casos individuais. As etapas envolvem leitura da descrição, do início ao fim, sem buscar qualquer interpretação ou identificação de atributo ou elemento, a fim de chegar a um sentido geral do que está descrito. Estas leituras foram realizadas quantas vezes foram necessárias. Após a obtenção do sentido, retomou-se a leitura do texto, apreendendo as unidades de significado, focalizadas no fenômeno pesquisado. As unidades de significados foram identificadas e revistas, selecionando-se o significado contido nestas unidades. Ao final da análise individual fezse a síntese das unidades transformadas em proposições, para se chegar a uma estrutura do fenômeno estudado.

$\mathrm{Na}$ análise nomotética, realizou-se a re-leitura das estruturas psicológicas individuais, para serem tomadas como referência a todos os casos. Buscaram-se evidências entre as proposições individuais, estabelecendo as convergências e divergências. Neste momento, as convergências passaram a ser afirmações, que puderam se tornar gerais e características de uma estrutura de fenômeno, e as divergências passaram a ser os aspectos estruturais idiossincráticos do fenômeno. Ao final, ocorreu a explicitação de generalidades, o momento da construção dos resultados, organizados em categorias, compreensão e elucidação do fenômeno.

Os resultados evidenciaram a aproximação das convergências e divergências quanto ao significado de cuidado, necessidades de cuidados dos pacientes ortopédicos percebidas pela equipe cirúrgica e ações de cuidado, que envolve as rotinas de trabalho da equipe de enfermagem e da equipe médica, voltadas para o cuidado perioperatório do paciente cirúrgico ortopédico.

Esta pesquisa foi submetida à análise de um Comitê de Ética em Pesquisa, conforme Resolução 466/12 do Conselho Nacional de Saúde com parecer $n^{\circ} 122 / 08$. Os entrevistados foram informados sobre os objetivos da pesquisa e assinaram o termo de consentimento livre e esclarecido. Para garantir fidedignidade, as falas dos pacientes foram identificadas pela letra $\mathrm{P}$. Quanto aos profissionais da saúde, utilizaram-se as letras referentes à sua categoria profissional: residentes médicos da clínica da ortopedia - RM e equipe de enfermagem - EE.

Este estudo faz parte de uma pesquisa mais ampla que investiga o cuidado perioperatório significados para o paciente, familiares, equipe de saúde e alunos - desenvolvida por professores do curso de enfermagem de uma universidade pública do Paraná.

\section{Apresentação dos Resultados}

A análise das entrevistas, realizadas com residentes médicos, equipe de enfermagem e pacientes da clínica ortopédica, resultou na construção de três categorias: Significado de cuidado; necessidades de cuidado dos pacientes ortopédicos percebidas pela equipe de saúde e ações de cuidado.

\section{Significado de Cuidado}

Os significados de cuidado expressos pelos residentes médicos abordaram: assistência completa, participar de todo o atendimento do paciente; curar o paciente; buscar conhecimento; estar disponível a qualquer momento; ter contato com o paciente; 
dar atenção ao paciente e à sua família; propiciar conforto; resolver problemas durante a internação, a alta hospitalar e nos retornos ambulatoriais; proteger-se e; realizar um bom trabalho em cada caso.

RM1: "A gente cuida resolvendo o problema do paciente [...] O foco é curar o problema, que está prejudicando o paciente".

RM2: "Participar de todo o atendimento do paciente".

RM3: "Estar disponível e disposto a qualquer momento".

RM4: "Estar atento às necessidades desse paciente, na medida do possível, nem sempre a gente consegue estar tão próximo assim".

RM4: "Determinado paciente que não é MR (multi - resistente), você pode muito bem tocar a mão nele, tocá-lo sem uma luva, que eu acho que é uma coisa que pode, o paciente pode sentir que o cara tá com medo de tocar em mim, que é substituível por uma lavagem de mão prévia e depois do contato".

A equipe de enfermagem revelou o cuidado como: dar apoio, associando o aspecto físico e o psicológico; ter carinho; atenção; não causar prejuízo; obrigação profissional; cuidar da família; atender às necessidades do outro; prevenção; proteção do trabalhador; prevenção de acidentes; cuidado paliativo.

EE3: "Eu vejo que a maior parte sempre precisa de um cuidado que não seja físico".

EE 5: "A gente está aqui para isso, para ajudar o paciente".

EE 2: "Cuidado para mim é você ver a pessoa como um todo. Não como uma tração ou, ah o membro elevado, é lembrar que acima do membro, da fratura de úmero, de rádio, sei lá ou de tíbia, existe uma pessoa".

EE9: "Para mim o cuidado é tudo. Não só a parte física, quanto a parte mental".

EE 8: "O cuidado é a gente se prevenir. É a prevenção. Você sempre ficar alerta para alguma coisa que poderá acontecer a qualquer momento, Eu acho que mais é a prevenção".
Os pacientes relacionaram cuidado com o cumprimento das orientações recebidas, ressaltando a importância destas orientações serem em linguagem acessível e clara. Relataram como sinônimo de cuidado: ajuda para a realização da higiene, deambulação, mobilização, administração de medicações e ações de autocuidado. Também associaram o cuidado com a percepção das necessidades do outro, privacidade, não exposição, acolhimento e saber fazer silêncio. Eles identificaram os enfermeiros como agentes do cuidado.

P2: "E a conversar também de quando está fazendo, explicar o que vai fazer, dar orientação".

P7: "O enfermeiro tem o cuidado para com seus pacientes, bom tudo que a gente faz se fizer com amor, você faz melhor, o meu trabalho mesmo, eu faço porque eu gosto então a gente faz com amor, o enfermeiro é a mesma coisa, então se ele gosta, ele tem que cuidar também".

P1: "Não expor".

Os significados apresentados pela equipe cirúrgica e pacientes revelam que, o cuidado é relacionado com diversos aspectos que envolvem a realidade de cada grupo estudado. Dentro do processo de trabalho, ele visa proporcionar uma assistência segura e que garanta o bem estar do cliente. Quanto ao cuidado, pacientes e equipe cirúrgica entendem a necessidade do cuidado subjetivo, que implica em atenção e reconhecem a necessidade de se autocuidarem. Observamos que o cuidado como obrigação profissional, foi citado pela equipe de enfermagem e pelos pacientes. $O$ cuidado relacionado com precaução de prejuízos para o paciente e proteção do trabalhador, envolvendo o uso de equipamentos de proteção individuais adequados, foi relatado tanto pelos médicos residentes, quanto pela equipe de enfermagem. O cuidado também foi associado com aspectos subjetivos tais como: carinho e satisfação, atenção, descritos pela equipe de enfermagem e pela equipe médica. A relação de cuidado com autocuidado apareceu nos discursos dos pacientes e dos profissionais da equipe de saúde. 


\section{Necessidades de Cuidados aos Pacientes Ortopédicos Percebidas pela Equipe de Saúde}

Nos discursos da equipe cirúrgica observou-se uma preocupação em identificar as necessidades de cuidados dos pacientes atendidos, bem como, buscar atender estas necessidades de maneira a garantir uma assistência integral.

Os residentes médicos abordaram em seus discursos a busca por uma assistência nutricional adequada, suprimento das necessidades psicológicas e clínicas do paciente, evidenciando uma preocupação com o cliente como um todo e não somente com sua afecção cirúrgica.

RM5: "Suprir as necessidades sejam elas psicológicas ou clínicas, mas é suprir as necessidades que o paciente necessita".

A equipe de enfermagem apresenta um olhar diferenciado para o cuidado com o paciente ortopédico. Em seus discursos relatam a realização de procedimentos, que viabilizam o processo de internação. Estes referem-se ao preparo préoperatório que colabora com o bom andamento do ato cirúrgico, aos cuidados no pós-operatório que relacionam-se à higiene, alimentação, analgesia, curativos e dispositivos (acesso venoso, sondas, drenos, tração) que acompanham a recuperação dos pacientes e estão diretamente relacionados ao seu bem estar, bem como às atribuições da enfermagem. Outro aspecto identificado e que acompanha os discursos da equipe médica, são os cuidados com a subjetividade do paciente, considerando seus sentimentos e sua individualidade na prestação de cada cuidado, de maneira a prestar uma assistência integral e humana.
EE5: "Tem que fazer o banho dele, no pré-operatório é muito importante a clorexidina, o banho com clorexidina em dois horários e levar ele para o centro cirúrgico já bem limpinho para evitar complicações por causa do pré-operatório, a osteomielite é muito alta".

EE3: “O que ele mais necessita que a gente faz...é mais a dor, esses pacientes queixam muito de dor, então a gente tem que medicar ele para que não tenham dor".

EE7: "Tudo para o conforto dele".

Observa-se que tanto as necessidades psicológicas e subjetivas quanto clínicas, dos pacientes ortopédicos, foram mencionadas pelos profissionais de enfermagem e pelos residentes médicos.

\section{Ações de Cuidado}

Esta categoria incluiu ações de cuidado, prestadas em todo o período perioperatório ao paciente cirúrgico ortopédico pela equipe de médicos residentes e de enfermagem e as ações realizadas na percepção dos próprios pacientes.

As ações de cuidado relatadas pelos residentes médicos estão relacionadas ao processo de internação e o tratamento prescrito durante este período, desde a prescrição de medicações como analgésicos e exames, cuidados necessários para o período perioperatório até a realização de orientações que, também devem acontecer durante todo o período de internação de maneira a sanar dúvidas sobre o diagnóstico e procedimento cirúrgico que necessita ser realizado, diminuindo a ansiedade e angústia do paciente, com explicações em linguagem acessível e clara para o entendimento dos pacientes e familiares. 
RM4: "Tento cercar por todos os lados para que a passagem do cara aqui, que normalmente é longa, seja o menos traumática possível".

RM5: "Geralmente o paciente não tem muito conhecimento de como vai ser o tratamento, geralmente o paciente está angustiado, tem medo da cirurgia, da anestesia, acho que o principal cuidado, assim como médico seria esclarecer, deixar o paciente mais esclarecido possível, menos ansioso, menos angustiado".

As ações de cuidados relatadas pela equipe de enfermagem, seguem os resultados apresentados na categoria anterior e dizem respeito à realização de procedimentos. No entanto, neste momento os profissionais apresentaram discursos mais específicos quanto aos cuidados em ortopedia. Relataram a administração de medicamentos com controle da dor, cuidados com a pele, principalmente por conta do longo período de imobilização (realização de curativo, prevenção de úlcera por pressão com mudança de decúbito), cuidados específicos no centro cirúrgico, que envolvem desde a recepção do paciente, realização do procedimento com disponibilização de todos os materiais necessários e cuidados com a recuperação anestésica e, novamente, cuidados com dispositivos ortopédicos.

EE2: "É o paciente que precisa de mais cuidados, porque vai ficar mais tempo acamado".

EE8: "Se tiver remédio quando o paciente se queixa de dor, eu vou medicar ele".

EE6: "O momento que ele volta da operação para a sala de recuperação [...] também tem a mesma característica dos outros pacientes. Uma anestesia geral que vai precisar colocar oxigenoterapia, verificar vias aéreas, capacidade pulmonar, sinais vitais, dor, perfusão do membro operado, dreno, quantidade de sangramento e bloqueio em anestesia geral, nível de bloqueio e verificar sinais vitais até ser encaminhado para a unidade. Como eu fico na sala de recuperação, eu atendo da mesma forma: recebo o paciente, fazendo aquela entrevista na admissão".
As ações de cuidados percebidas pelos pacientes dizem respeito aos cuidados vivenciados por eles com o auxílio da equipe médica e de enfermagem. Os pacientes enfatizaram os cuidados técnicos recebidos: preparo para a cirurgia e cuidados prestados no centro cirúrgico, utilização de medicações, inclusive analgésicos, auxílio recebido para alimentação, higiene e realização de fisioterapia. Ressaltaram a importância da não omissão dos fatos para gerar tranquilidade, consolo e minimização do medo, como medida de cuidado citaram as orientações recebidas, inclusive as orientações para alta. Identificaram como agentes de cuidado: os médicos, a equipe de enfermagem, fisioterapeutas e alunos.

P1: "E depois da cirurgia também conversaram comigo, ficaram o tempo todo até eu voltar da anestesia".

P2: "Não esconde nada de ninguém e não fala nada que é mentira e fala o que é certo, o que vai dar certo, o que vai fazer".

P3: "O médico a todo o momento perguntou se estava tudo bem, se eu estava sentindo alguma coisa".

P5: "Quando tiver dúvida, até estar com vergonha de falar com o médico, mas a gente pergunta, eles (os alunos) explicam bem orientando tudo direitinho".

Dentre as ações de cuidados relatadas, observase que o preparo cirúrgico, as medicações e cuidados com a dor foram citadas pelos profissionais da equipe de saúde e pelos pacientes. Quanto ao preparo cirúrgico a equipe de enfermagem se reconhece como a responsável pelo preparo físico para a cirurgia, e a equipe médica pelas prescrições de medicações e exames, demonstrando uma complementaridade dos trabalhos de uma equipe com a outra. Observa-se a ênfase dada a analgesia por todos. 
Observamos que a atenção para o risco cirúrgico foi apresentada por ambas as equipes de profissionais, e que, o cuidado com a avaliação e identificação de patologias associadas é executado pela equipe médica, no entanto, é percebida e relatada pelos pacientes.

A equipe de enfermagem citou cuidados com sondas, drenos, posicionamento, higiene, locomoção, curativos, estes três últimos também foram lembrados nos discursos dos pacientes.

Relacionados aos cuidados intra-operatórios apareceram nos discursos da equipe de enfermagem: posicionamento, encaminhamentos dentro do centro cirúrgico, admissão, instrumentação, cuidados na sala de recuperação anestésica, transporte, interação, sendo os dois últimos percebidos por meio das falas dos pacientes.

Os cuidados para prevenção de complicações no período perioperatório foram citados pelos médicos e pela equipe de enfermagem. Foi possível observar que a equipe de enfermagem apresentou discursos mais ricos e com mais detalhes, enquanto a equipe médica foi mais objetiva.

$\mathrm{Na}$ percepção da equipe médica o cuidado foi compartilhado com seus colegas docentes, residentes e internos; com a enfermagem; a fisioterapia e com alguns pacientes. Referiram que não compartilharam as ações de cuidado com todos os pacientes, em virtude do estado físico e mental de alguns deles. Porém, ressaltaram a necessidade do envolvimento com os pacientes para a produção do cuidado em saúde. Na percepção da equipe de enfermagem, o cuidado foi compartilhado entre a equipe médica e a de enfermagem de maneira satisfatória.

\section{Discussão}

A aproximação dos significados de cuidado, expressos pelos participantes da pesquisa, revelou que o cuidado está relacionado com as atividades técnicas dos profissionais em benefício do bem estar e recuperação dos pacientes, bem como, com o zelo pelas necessidades psicológicas destes.

A necessidade de uma assistência integral foi evidenciada, tanto pela equipe médica, quanto pela de enfermagem. Chama a atenção o fato de, os profissionais de saúde associarem o cuidado, com a integralidade e com as repercussões sociais da doença na vida dos pacientes.

$\mathrm{O}$ atendimento ao paciente ortopédico não se resume, apenas às ocorrências anátomo-patológicas, visto que as diferentes lesões que o indivíduo apresenta produzirão diferentes necessidades de cuidados médicos e de enfermagem. Além disso, o paciente sofrerá de maneira física e psicológica com as limitações que a doença produzirá no seu cotidiano. Portanto, a técnica tem que complementar a comunicação, uma vez que esta constitui o elo na interação entre profissional e paciente possibilitando o cuidado e a produção de saúde (HAYASHI; GARANHANI, 2012).

Observou-se que houve diferença entre o foco do cuidado para a enfermagem e para a medicina, sendo que, para a enfermagem o cuidado teve um foco assistencial holístico e para a medicina um foco curativo, com o objetivo de tratamento. Os residentes médicos justificaram esta posição pela dificuldade de estarem mais próximos dos pacientes para o desenvolvimento do cuidado holístico, devido a falta de tempo, assim como pela própria formação acadêmica.

Os profissionais da área da saúde ainda possuem uma formação muito voltada para o modelo biomédico centrado no diagnóstico e tratamento das doenças. O médico tem o ensino acadêmico predominantemente na ação curativa, o que prejudica a assistência holística ao paciente, porque divide o corpo em partes isoladas. Quando o objeto de atenção limita-se ao tratamento voltado à doença, e não ao paciente, corta-se um elo essencial para o sucesso do cuidado com o paciente (PERIM et al., 2009).

A cura da doença é demasiadamente importante, 
mas ainda mais importante é o doente. Neste contexto, está a relevância do cuidado prestado pela equipe de enfermagem. $\mathrm{O}$ cuidado de enfermagem só é possível quando há uma integração entre paciente e profissional. Uma estratégia eficaz na construção do cuidado é a utilização da Sistematização da Assistência de Enfermagem (SAE), que constitui um método que organiza e qualifica o trabalho do enfermeiro. Esta não orienta apenas o enfermeiro, mas também sua equipe na prestação de cuidados integrais e individualizados ao paciente (VENTURINI; MATSUDA; WAIDMAN, 2009). Por assistirem ao paciente durante 24 horas, é necessário que os profissionais de enfermagem reflitam a assistência ao paciente cirúrgico, para avaliar as reais necessidades de cada um.

O desempenho de um profissional não se alimenta apenas das condições materiais e sabedoria técnico-científica. É necessária a articulação entre o ser técnico, o trabalhador e o ser social, do contrário ocorrem despersonificações do cuidado e desumanização da assistência (WALDOW; BORGES, 2011). Assim, um grande desafio, na área da saúde, está na adoção de estratégias humanizadoras no âmbito assistencial, que permitam a valorização dos aspectos subjetivos do paciente durante o seu tratamento (SILVA; SILVEIRA, 2011).

Observamos que os significados de cuidado para os pacientes ficaram próximos das suas necessidades presentes, ou seja, desencadeadas pelo próprio processo saúde e doença. Assim, estes resultados evidenciaram necessidades de cuidado que podem ser associadas às necessidades humanas básicas.

Com a ocorrência do trauma ortopédico, surgem necessidades específicas frente ao processo saúde e doença, pois, este, resulta em diferentes graus de dependência, que repercutem na autonomia do paciente. Mesmo que seu estado clínico seja estável, o paciente que possui uma fratura, ou que é submetido a um procedimento cirúrgico ortopédico, na maioria das vezes, adquire alguma limitação, inclusive para realização de atividades rotineiras, como alimentação e cuidados com a higiene (ALVES et al., 2011).

O período perioperatório é permeado por diversos sentimentos: medo do procedimento cirúrgico e da anestesia, incertezas e receio de alterações no estilo de vida. A equipe de saúde vem a ser a responsável pela educação do paciente, sendo o enfermeiro o elo entre o paciente e toda a equipe de saúde. $O$ vínculo deve ser criado desde o momento de decisão da cirurgia, com o objetivo de minimizar esses anseios por meio das orientações, esclarecendo dúvidas quanto ao ato cirúrgico, ao período pós-operatório e às demais dúvidas. O modo como o paciente encara a vivência de uma cirurgia reflete em sua recuperação. As orientações podem abranger a autonomia do paciente, possibilitando que este se reconheça como agente de seu cuidado e produtor de sua saúde (TENANI; PINTO, 2007).

Assim, observamos que a percepção de cuidado, neste momento crítico, ficou bastante restrita frente à condição clínica. Ressaltamos que os participantes tiveram dificuldades em dar uma resposta imediata sobre a questão, necessitando muitas vezes de uma pausa para reflexão. Acrescentamos o possível limite de pensar o cuidado de uma forma mais abrangente no momento da entrevista.

Quanto às necessidades específicas do paciente ortopédico, todas foram relacionadas com cuidados com o trauma: cuidados com curativos, posicionamento, drenos, sondas, tração, úlcera por pressão, dor, sinais vitais, medicações, observação de complicações.

Um estudo sobre diagnósticos de enfermagem, em pacientes ortopédicos internados em uma unidade médico-cirúrgica constatou a relevância na ocorrência de: risco de infecção, dor, constipação, intolerância a atividade, distúrbio no padrão do sono, mobilidade física prejudicada e integridade da pele alterada. Além disso, as autoras apresentam 
a importância dos profissionais perceberem e diagnosticarem condições pouco frequentes, que, se identificadas e tratadas, permitirão a individualização do cuidado (SILVA; VIANA; VOLPATO, 2008). Esses resultados justificam o preparo dos profissionais da área de ortopedia para manuseio dos diferentes dispositivos e prevenção de prejuízos na assistência ao paciente.

O cuidado relacionado ao tratamento e prevenção da dor foi mencionado pelos profissionais de saúde e pacientes. No período pós-operatório, as cirurgias ortopédicas estão diretamente associadas com a dor de intensidade moderada a forte. A experiência dolorosa, neste período, é citada pelos pacientes, por isso, é necessária uma atenção especial para a analgesia a ser administrada (PAULA et al., 2011).

A dor é considerada o quinto sinal vital, sendo uma sensação subjetiva e de merecida importância, porque traz consigo repercussões sistêmicas e influencia diretamente a recuperação do paciente cirúrgico, assim como a morbidade e complicações pós-operatórias. Os benefícios da analgesia adequada são certos, uma vez que, esta melhora a qualidade do atendimento, proporciona maior bem estar ao paciente, controla o estresse físico e permite avanços em sua recuperação (PAULA et al., 2011; GIANCOLI et al., 2012).

Os profissionais de saúde discursaram sobre a necessidade de prevenção de acidentes, com material biológico, o que nos remete a reflexões sobre a importância da biossegurança, como componente de cuidado no ambiente cirúrgico.

Biossegurança é o conjunto de ações consideradas seguras e adequadas à manutenção da saúde do profissional, à preservação do meio ambiente e à qualidade dos resultados, ao executar atividades que ofereçam risco de aquisição de doenças profissionais e, principalmente, que visam evitar a exposição de profissionais a agentes infecciosos, tóxicos ou radioativos dentro do ambiente hospitalar. Abrange também: medidas de controle e observação, quando da ocorrência de acidentes biológicos involuntários; realização de investigações sistemáticas, para ampliar o conhecimento sobre os riscos decorrentes das próprias medidas de biossegurança, incluindo a supervisão e o controle de sua aplicação (SOCIEDADEBRASILEIRADEENFERMEIROS DE CENTRO CIRÚRGICO, 2013).

As medidas para prevenção de acidentes, apontadas pelos profissionais, somadas ao seguimento das orientações recebidas, apresentadas pelos pacientes, constituem as ações de autocuidado mencionadas pelos participantes. O autocuidado é a prática de atividades que os indivíduos iniciam e executam em favor próprio, na manutenção da vida, saúde e bem-estar (OREM, 2001). Assim, observa-se a importância do autocuidado, tanto para quem é cuidado, quanto para o cuidador, ressaltando a importância dos serviços de saúde em promover estratégias que visem melhores condições de trabalho aos profissionais, uma vez que ao se cuidarem, poderão colaborar no estímulo ao autocuidado junto aos pacientes.

\section{Considerações Finais}

Os resultados deste estudo evidenciaram que os significados de cuidado para pacientes ortopédicos e profissionais de saúde da ortopedia relacionaram-se a atividades técnicas dos profissionais, em benefício do bem estar e recuperação dos pacientes, bem como, com o zelo pelas necessidades psicológicas destes, em especial, dedicar atenção e realizar orientações, além da prevenção de acidentes pelos profissionais.

As necessidades dos pacientes percebidas pela equipe de saúde retrataram as necessidades humanas básicas e a assistência para o ato cirúrgico ortopédico. As ações de cuidado revelaram a preocupação com o planejamento da assistência ao cliente e a integração entre os profissionais no desenvolvimento do cuidado. 
Os resultados apontaram diversas maneiras de cuidar e a forma como os participantes deste estudo atuaram neste processo. A identificação destes aspectos é relevante, pois caracteriza de maneira mais detalhada como o cuidado em ortopedia tem se consolidado na população em estudo. No entanto, novas pesquisas ainda se fazem necessárias para aprofundar a compreensão do tema, alcançando assim, uma percepção mais profunda sobre o cuidado ao paciente ortopédico.

O cuidado acontece a partir das necessidades percebidas pelas pessoas e da magnitude de seu significado, sendo este dinâmico e atemporal. O exercício do cuidar é importante, porque abarca a questão da subjetividade e da ética. Somos responsáveis pelas experiências que o doente tem, assim como pelas oportunidades que podemos criar para que ele possa ressignificar suas experiências pregressas.

\section{Referências}

ALVES, M. V. M. F. F.; MESSORA, T. C. C.; GONÇALVES, S. P. A.; LUPPI, C. H. B. Avaliação do grau de dependência de pacientes em enfermaria de ortopedia de um hospital escola. Revista Eletrônica de Enfermagem, Goiânia, v. 13, n. 4, p. 612-9, 2011.

BRASIL. Ministério da Saúde. Datasus: informações de saúde (TABNET). Indicadores de Saúde. Disponível em: <www2.datasus.gov.br/ DATASUS/index.php?area $=0201>$. Acesso em: 19 maio 2010.

GIANCOLI, L. G. T.; FONSECA, M. A. F. L. A.; CONSTANTINO, E.; PIRES, O. C.; POSSO, I. P. Palestra e manual sobre tratamento da dor, não alteraram a prescrição de analgésicos no pósoperatório de cirurgias ginecológicas. Revista Dor, São Paulo, v. 13, n. 4, p. 338-42, 2012.

HAYASHI, J. M.; GARANHANI, M. L. O cuidado perioperatório ao paciente ortopédico sob o olhar da equipe de enfermagem. REME: Revista Mineira de Enfermagem, Belo Horizonte, v. 16, n. 2, p. 208216, 2012.
MARTINS, J.; BICUDO, M. A. V. A pesquisa qualitativa em psicologia: fundamentos e recursos básicos. 2. ed. São Paulo: Moraes, 2005.

MELIONE, L. P. R.; MELLO-JORGE, M. H. P. Gastos do Sistema Único de Saúde com internações por causas externas em São José dos Campos, São Paulo, Brasil. Cadernos de Saúde Pública, Rio de Janeiro, v. 24, n. 8, p. 1814-24, 2008.

MELLO, D. F.; LIMA, R. A. G. O cuidado de enfermagem e a abordagem Winnicottiana. Texto \& Contexto-Enfermagem, Florianópolis, v. 19, n. 3, p. 563-9, 2010.

OREM, D. E. Nursing: concepts of practice. New York: Mosby-Year Book, 2001.

PAULA, G. R.; REIS, V.S.; RIBEIRO, F. A.; GAGLIAZZI, M. T. Assistência de enfermagem e dor em pacientes ortopédicos na recuperação anestésica, no Brasil. Revista Dor, São Paulo, v. 12, n. 3, p. 265-69, 2011.

PERIM, G. L.; ABDALLA, I. G.; AGUILAR-DASILVA, R. H.; LAMPERT, J. B.; STELLA, R. C. R.; COSTA, N. M. S. C. Desenvolvimento docente e a formação de médicos. Revista. Brasileira de Educação. Médica, Rio de Janeiro, v. 33, supl. 1, p. 70-82, 2009.

QUEIROZ, M. V. O.; RIBEIRO, E. M. V.; PENNAFORT, V. P. S. Assistência ao adolescente em um serviço terciário: acesso, acolhimento e satisfação na produção do cuidado. Texto \& Contexto-Enfermagem, Florianópolis, v. 19, n. 2, p. 291-9, 2010.

ROTHROCK, J. C. (Ed.). Alexander: cuidados de enfermagem ao paciente cirúrgico. 13. ed. Rio de Janeiro: Elsevier, 2007.

SARAGIOTTO, I. R. A.; GARANHANI, M. L. Significado do cuidado perioperatório para os residentes de medicina na ortopedia de um hospital universitário. 2010. 66 fls. Monografia (Especialização em Enfermagem em Centro Cirúrgico e Centro de Material Esterilizado) Faculdade Estadual de Educação, Ciências e Letras de Paranavaí, Paranavaí. 2010. 
SILVA, I. D.; SILVEIRA, M. F. A. A humanização e a formação do profissional em fisioterapia. Ciência \& Saúde Coletiva, Rio de Janeiro, v. 16, supl. 1, p. 1535-46, 2011.

SILVA, F. S.; VIANA, M. F.; VOLPATO, M. $\mathrm{P}$. Diagnósticos de enfermagem em pacientes internados pela clínica ortopédica em unidade medico-cirúrgica. Revista Gaúcha de Enfermagem, Porto Alegre, v. 29, n. 4, p. 565-72, 2008.

SOCIEDADE BRASILEIRA DE ENFERMEIROS DE CENTRO CIRÚRGICO - SOBECC. Recuperação anestésica e centro de material e esterilização. Práticas recomendadas SOBECC. 6. ed. São Paulo: SOBECC, 2013.

STUMM, E. M. F.; ZIMMERMANN, M. B.; GIRARDON-PERLINI, N. M; KIRCHNER, R. M. Ações do enfermeiro na recepção do paciente em centro cirúrgico. REME: Revista Mineira de Enfermagem, Belo Horizonte, v.13, n.1, p.99-106, 2009.

TENANI, A. C.; PINTO, M. H. A importância do conhecimento do cliente sobre o enfrentamento do tratamento cirúrgico. Arquivos de Ciência da Saúde, São José do Rio Preto, v. 14, n. 2, p. 81-7, 2007.

VENTURINI, D. A.; MATSUDA, L. M.; WAIDMAN, M. A. P. Produção científica brasileira sobre sistematização da assistência de enfermagem. Ciência Cuidado \& Saúde, Maringá, v. 8, n. 4, p. 707-715, 2009.

WALDOW, V. R.; BORGES, R. F. Cuidar e humanizar: relações e significados. Acta Paulista de Enfermagem, São Paulo, v. 24, n. 3, p. 414-8, 2011. 